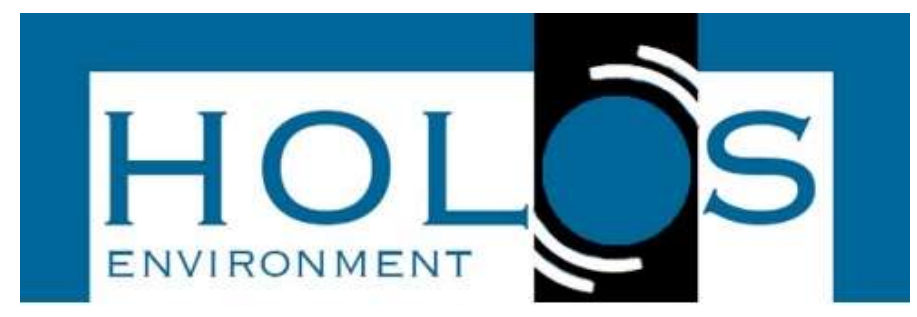

\title{
QUANTIFICAÇÃO DO POTENCIAL TEÓRICO DE APROVEITAMENTO ENERGÉTICO DO BIOGÁS NO ATERRO SANITÁRIO DE SABARÁ/MG
}

\author{
THEORETICAL POTENTIAL QUANTIFICATION OF BIOGAS ENERGY \\ UTILIZATION IN SABARÁ / MINAS GERAIS STATE SANITARY LANDFILL
}

\author{
Alefe Marques dos Reis ${ }^{1}$; Alessandra Alves da Cruz ${ }^{1}$; \\ Júlia Machado Botelho ${ }^{1}$
}

Artigo recebido em: 08/12/2017 e aceito para publicação em: 19/10/2018.

DOI: http://dx.doi.org/10.14295/holos.v18i2.12251

Resumo: Os aterros sanitários contêm grande parcela de matéria orgânica devido à deposição de resíduos em suas células. A decomposição dessa matéria gera gases, como o metano, que é produzido em grande quantidade e que é o principal responsável pelo potencial energético do biogás. Diante da necessidade de diversificar a matriz energética do País para produção de eletricidade e de reduzir a emissão de gases de efeito estufa na atmosfera, a utilização do biogás pode revelar-se vantajosa. $O$ objetivo deste estudo foi quantificar o potencial teórico do aproveitamento energético do biogás no aterro sanitário de Sabará/MG. Para isso, foi quantificada a geração de gás metano durante a vida útil do aterro. A partir desse ponto, determinou-se a potência de geração de energia e a quantidade de famílias que poderiam ser atendidas com esse potencial energético. Os resultados encontrados indicam que $\mathrm{o}$ aterro poderá produzir teoricamente, em seu $13^{\circ}$ ano, $510.316,52 \mathrm{~m}^{3}$ de metano, capaz de gerar uma potência máxima de $4.312,11 \mathrm{KW} / \mathrm{ano}$, atendendo o equivalente a 19.674 famílias.

Palavras-chave: Resíduos Sólidos. Aterro Sanitário. Biogás. Energia.

Abstract: Landfills contain a large amount of organic matter, due to the deposition of residues in its cells. The decomposition of organic matter generates gases, such as methane, which is generated in large quantities and which is the main constituent responsible for the energy potential of biogas. To face the need to diversify the Brazilian energy matrix and to reduce the emission of greenhouse gases, the use of biogas may present some advantages. The objective of this study was to quantify the theoretical potential of the biogas energy utilization in the Sabará / MG landfill. For this, the methane gas generation during the life of the landfill was quantified. From this point, the power of power generation and the number of families that could be met with this energy potential were determined. The results show the landfill will produce in its 13 th year about $510,316.52 \mathrm{~m}^{3}$ of methane, capable of generating a maximum power of 4,312.11 KW / year, serving around 19,674 families.

Palavras-chave: Solid Waste. Landfill. Biogas. Energy.

\footnotetext{
${ }^{1}$ Centro Universitário Metodista Izabela Hendrx, Belo Horizonte, MG. E-mails:

(alefe.marques@hotmail.com, alessandralves.c@gmail.com, julinha1708@gmail.com)
} 


\section{INTRODUÇÃO}

Devido ao crescimento populacional e ao desenvolvimento industrial e tecnológico, cresce a demanda por consumo de energia. Tendo em vista que muitas fontes energéticas atualmente utilizadas são limitadas e não renováveis, é possível que daqui a algumas décadas essas fontes se esgotem (EPE, 2015).

Segundo Sauer et al., (2001), no período entre 1991 e 2001, a demanda por energia cresceu em média $4,1 \%$ ao ano, enquanto a oferta cresceu apenas 3,3\%. Com isso, retirou-se dos reservatórios das usinas mais água do que entrou com as chuvas. Após o racionamento de energia elétrica ocorrido nessa época, a diversificação da matriz energética tornou-se um fator estratégico, favorecendo a geração de fontes alternativas como biomassa, biogás, eólica, entre outras (SILVA E CAVALIERO S.D. apud VANZIN, 2006).

Na gestão de resíduos sólidos urbanos, existem vários processos para o tratamento e a disposição final ambientalmente correta dos resíduos, sendo que o mais utilizado ainda é o aterro sanitário, "devido aos custos inferiores quando comparados a outras tecnologias utilizadas no gerenciamento de resíduos sólidos" (CASSAU FILHO, 2012). Os aterros sanitários são apontados como a alternativa legalmente adequada para a disposição final dos resíduos sólidos urbanos devido à utilização de mecanismos corretos para a impermeabilização do solo, cobertura dos resíduos, captação do chorume e captação e queima do biogás.

Segundo a Associação Brasileira de Empresas de Limpeza Pública e Resíduos Especiais - ABRELPE (2015), a geração dos Resíduos Sólidos Urbanos - RSU no Brasil foi da ordem de 79,9 milhões de toneladas em 2015. Desses resíduos, cerca de 42,6 milhões de toneladas são destinadas para os aterros sanitários.

O interesse na produção de energia a partir de fontes alternativas abriu portas para vários estudos sobre o biogás gerado em aterros sanitários, que é um subproduto obtido pela decomposição anaeróbia da matéria orgânica para o seu aproveitamento na geração de energia elétrica. A conversão biológica dos resíduos para fins energéticos tem-se tornado cada vez mais relevante e vantajosa, devido ao grande volume de resíduos gerados, apresentando-se como uma fonte interessante de energia alternativa (MELLO et al., 2014).

Segundo o Ministério do Meio Ambiente - MMA (2017), o biogás é composto por várias substâncias, algumas presentes em grandes quantidades, como o metano 
e o dióxido de carbono, e outras em quantidades em traços, como o nitrogênio, a amônia, o monóxido de carbono, entre outros. O gás metano é o principal responsável pelo potencial energético do biogás, chegando a representar de $45 \%$ a $60 \%$ de sua composição (ELK, 2007).

De acordo com Cassau Filho (2012), o biogás de aterros sanitários é utilizado como fonte de energia em vários locais do mundo e, devido ao seu potencial energético, pode ser utilizado para diversas aplicações, como geração de energia elétrica, abastecimento de gás domiciliar, combustível para veículos, entre outros.

Com isso, estudos de quantificação e viabilidade do potencial de geração de biogás nos aterros do Brasil são de extrema importância tanto para diversificar a matriz energética quanto para diminuir a emissão do gás metano para a atmosfera, contribuindo para a redução dos efeitos das mudanças climáticas.

O presente estudo teve como objetivo quantificar o potencial teórico do aproveitamento energético do biogás no aterro sanitário Centro de Tratamento de Resíduos Macaúbas (CTR Macaúbas), localizado no município de Sabará - MG, Região Metropolitana de Belo Horizonte, e delimitado pelas cidades de Belo Horizonte, Caeté, Nova Lima, Raposos, Santa Luzia e Taquaraçu de Minas (PREFEITURA DE SABARÁ, 2017).

\section{MATERIAL E METÓDOS}

\subsection{Procedimentos}

O aterro em estudo iniciou sua operação em 2010 e tem a estimativa de vida útil de 20 anos, com uma área disponível de 50 hectares, recebendo os resíduos de 14 municípios, atendendo aproximadamente a 624 mil pessoas, com um recebimento anual de 1.332.000 toneladas de resíduos (CTR MACAÚBAS, 2017).

Segundo Gil (2008), a pesquisa exploratória tem como objetivo proporcionar maior familiaridade com o problema, com vistas a torná-lo mais explícito ou a construir hipóteses. Pode envolver levantamento bibliográfico, entrevistas com pessoas experientes no problema pesquisado e análise de exemplos. Geralmente, assume a forma de pesquisa bibliográfica e estudo de caso.

A pesquisa desenvolvida é um estudo de caso, classificado, com base em seus objetivos, como pesquisa exploratória, devido ao levantamento qualitativo do tema: 
aproveitamento do biogás de aterro sanitário para geração de energia. Consultou-se também a metodologia do Banco Mundial (2004) utilizada para o cálculo da estimativa do volume de biogás em aterros sanitários. Em seguida, realizou-se o cálculo do potencial energético, avaliando-se a capacidade e a viabilidade de utilização do aterro para geração de energia. Para isso, foi realizada uma análise da quantidade de famílias que poderão ser atendidas com a energia gerada. Além disso, estimou-se a emissão de gases de efeito estufa que deixariam de ser emitidos caso fosse implementado o aproveitamento energético do biogás. Para esse cálculo, foi utilizado o potencial de aquecimento global de conversão do metano $\left(\mathrm{CH}_{4}\right)$ para dióxido de carbono $\left(\mathrm{CO}_{2}\right)$ de 25, ou seja, cada 1 tonelada de $\mathrm{CH}_{4}$ emitida por um aterro sanitário é equivalente a 25 toneladas de $\mathrm{CO}_{2}$ (IPCC, 2007).

\subsubsection{Quantificação do metano gerado}

Segundo o Banco Mundial (2004), o método conhecido por Scholl Canyon pode ser utilizado, conforme a equação 1 , para a quantificação da geração de metano em aterros:

$Q_{\left(\mathrm{CH}_{4}\right) i}=k \times L_{0} \times m_{i} \times e^{-k . t}$

em que:

$Q_{\left(\mathrm{CH}_{4}\right)}$ é o metano produzido no ano $i$ a partir da seção $i$ do resíduo, ( $\mathrm{m}^{3} / \mathrm{ano}$ );

$k$ é a constante da geração de metano, $\left(\mathrm{ano}^{-1}\right)$;

$L_{0}$ é o potencial da geração de metano, $\left(\mathrm{m}^{3} \mathrm{CH}_{4} / t\right.$ resíduos);

$m_{i}$ é a massa de resíduo despejada no ano $i$, (t/ano); e

$t$ é o tempo desde o encerramento do aterro, ou célula, anos ( $t=0$ para aterros ativos).

Para obtenção dos resultados, utilizou-se para a constante de geração $k$ o valor de 0,06 , considerando que os resíduos são moderadamente degradáveis e o volume pluviométrico anual da região é de aproximadamente 1.370 mm (CLIMA DATA, 2017). Em relação ao potencial da geração de metano, utilizou-se o valor $L_{0}$ de aproximadamente $170 \mathrm{~m}^{3}$ de metano para cada tonelada de resíduos domésticos (EPA, 2005). Para estimar o total de metano gerado durante a vida útil do aterro, foi utilizada a 
massa de resíduos gerada anualmente, considerando a taxa de crescimento populacional de 1\% ao ano (FELCA, 2015). Como o aterro em estudo já se encontrava em operação há 7 anos, os resultados foram obtidos levando-se em conta os dados atuais e as projeções para os próximos 13 anos de vida útil.

\subsubsection{Quantificação do potencial energético}

Para calcular o potencial energético, foi utilizado o modelo sugerido pela CETESB (CETESB, 2006 apud MELLO et al., 2014), apresentado pela equação 2:

$$
P x=\left[\left(Q * \frac{P c_{(} \mathrm{CH}_{4)}}{31536000}\right) * E C *\left(\frac{K}{100}\right)\right]
$$

em que:

$P_{x}$ é a potência disponível por ano $(\mathrm{KW}$ ano-1 $)$;

$Q$ é a vazão do $\mathrm{CH}_{4}$ por ano $\left(\mathrm{m}^{3}\right.$ ano-1);

$P_{c(\mathrm{CH} 4)}$ é o poder calorífico do $\mathrm{CH}_{4}$ por ano $=35,53 \cdot 10^{3} \mathrm{~J} \mathrm{~m}^{-3}$;

31.536.000 é a quantidade de segundos por ano $\left(\mathrm{s} \mathrm{ano}^{-1}\right)$;

$E_{c}$ é a eficiência de coleta de gases (75\%); e

Ké a constante de conversão, igual a 1.000;

A eficiência na coleta do biogás foi de $75 \%$, considerando que ele passa por um tratamento em que somente o metano é aproveitado (CETESB, 2006 apud MELLO et al., 2014).

\subsubsection{Quantificação de famílias atendidas pela energia gerada no aterro}

Para estimar a quantidade de famílias que serão atendidas durante o tempo de geração do metano e de acordo com a potência produzida, foram utilizadas as equações 3, 4 e 5, segundo o Ministério de Minas e Energia - MME (2017):

Energia Consumida (ano/família) = Energia consumida (mês/família) x 12 meses 
Número de Famílias Atendidas = Energia Consumida (ano) / Energia consumida (ano/família)

A partir das informações coletadas, foram elaboradas planilhas eletrônicas do software Microsoft $\circledast$ Excel (2011) e gerados gráficos. Esses dados foram submetidos a um processo de análise, que levou aos resultados aqui expostos.

\section{RESULTADOS E DISCUSSÃO}

\subsection{Modelo de geração do biogás - Banco Mundial}

Os resultados obtidos no presente estudo demonstram a curva de geração de metano, permitindo observar a tendência de produção do gás em relação aos anos em que o aterro está ativo e o posterior decaimento com o encerramento da vida útil. $\mathrm{Na}$ Figura 1 está apresentada a geração de $\mathrm{CH}_{4}$ para a massa de resíduos sólidos urbanos depositados no aterro de Sabará.

Figura 1 - Geração de $\mathrm{CH}_{4}$ para a massa de resíduos sólidos urbanos depositados

\section{Geração de Metano $\left(\mathrm{m}^{3} / \mathrm{ano}\right)$}

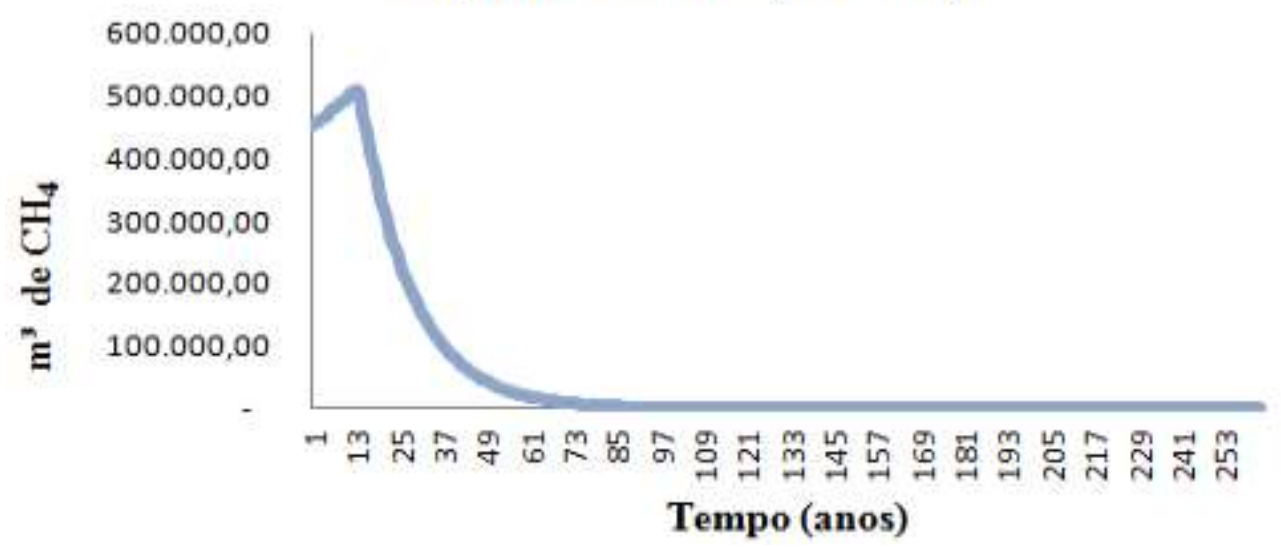

Fonte: Autores (2017)

É possível notar que o pico máximo de geração de metano ocorre no $13^{\circ}$ ano, ou seja, último ano de vida útil do aterro (2030), momento em que a decomposição está acontecendo aceleradamente com a grande massa de resíduos que foi depositada durante todos os anos, apresentando um valor de 510.316,52 m³/ano. Com o 
fechamento do aterro, como não haverá mais o descarte de resíduos no local, a decomposição ocorrerá somente para a massa que já estava depositada, começando então a decair e apresentando, a partir do $61^{\circ}$ ano, menor geração de metano, até aproximar-se de zero.

O padrão encontrado na Figura 1 segue o mesmo padrão estabelecido no estudo elaborado por Felca (2015), no qual foi realizada a Estimativa do Potencial Energético de um aterro sanitário por meio de duas metodologias, sendo uma delas a utilizada neste estudo, o que ajuda a validá-lo.

\subsection{Potencial Energético}

Utilizando-se dos valores de emissão de metano calculados pelo modelo desenvolvido pelo Banco Mundial, gerou-se uma curva de potencial energético. Essa curva, apresentada na Figura 2, foi obtida através da equação 2.

Figura 2 - Potência produzida pela energia gerada no aterro durante sua vida útil

\section{Potência Disponível (kW/ano)}

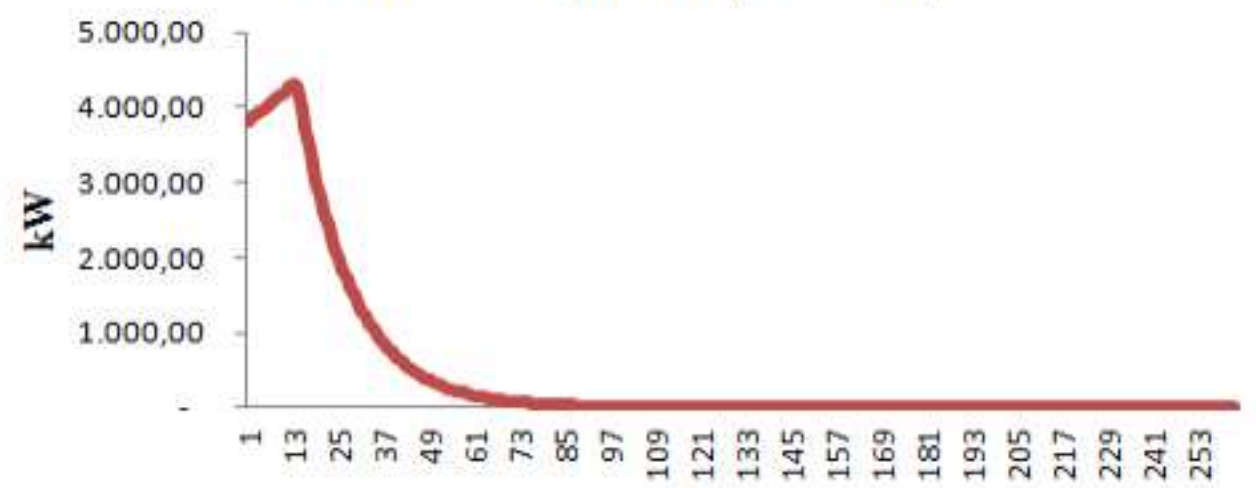

Fonte: Autores (2017)

\section{Tempo (anos)}

Observa-se, na Figura 2, que, ao longo do tempo, após o fim de vida útil do aterro, como não se tem mais o depósito de resíduos, a decomposição da matéria orgânica tende a diminuir, ocorrendo um decréscimo na produção do biogás e consequente diminuição da potência, podendo-se dizer então que as Figuras 1 e 2 estão proporcionalmente ligadas. Com isso, mesmo havendo a ocorrência de um elevado ponto de potência, é necessário considerar a variação da vazão que ocorre com o tempo, para se fazer o dimensionamento de uma central para aproveitamento de biogás, já que, a partir do $61^{\circ}$ ano, a potência é baixa e tende a zero. 
Observando as Figuras 1 e 2, nota-se que o comportamento apresentado era esperado para a produção de biogás no aterro, com uma acelerada produção de metano nos primeiros anos e atingimento da produção máxima em 20 anos, ou seja, no $13^{\circ}$ ano calculado. Nota-se também que a potência apresenta a mesma tendência de produção, havendo, depois desse período, uma queda na produção, que chega a zero após os 100 anos (BARROS, 2012).

\subsection{Quantificação de famílias atendidas no ano de geração máxima de energia do aterro}

De acordo com a Resenha Mensal do Mercado de Energia Elétrica da Empresa de Pesquisa Energética (EPE, 2017), desde fevereiro de 2017 o consumo médio nas unidades residenciais está praticamente estacionário em 160 kWh/mês. Em julho de 2017, o consumo de energia elétrica no Brasil atingiu $45.838 \mathrm{GWh}$, sendo $22,7 \%$ de uso residencial, ou seja, 10.389 GWh (MME, 2017).

A Figura 3 apresenta a quantidade de famílias que podem ser atendidas com a produção de energia elétrica através do biogás gerado no aterro em estudo.

Figura 3 - Quantidade de Famílias atendidas

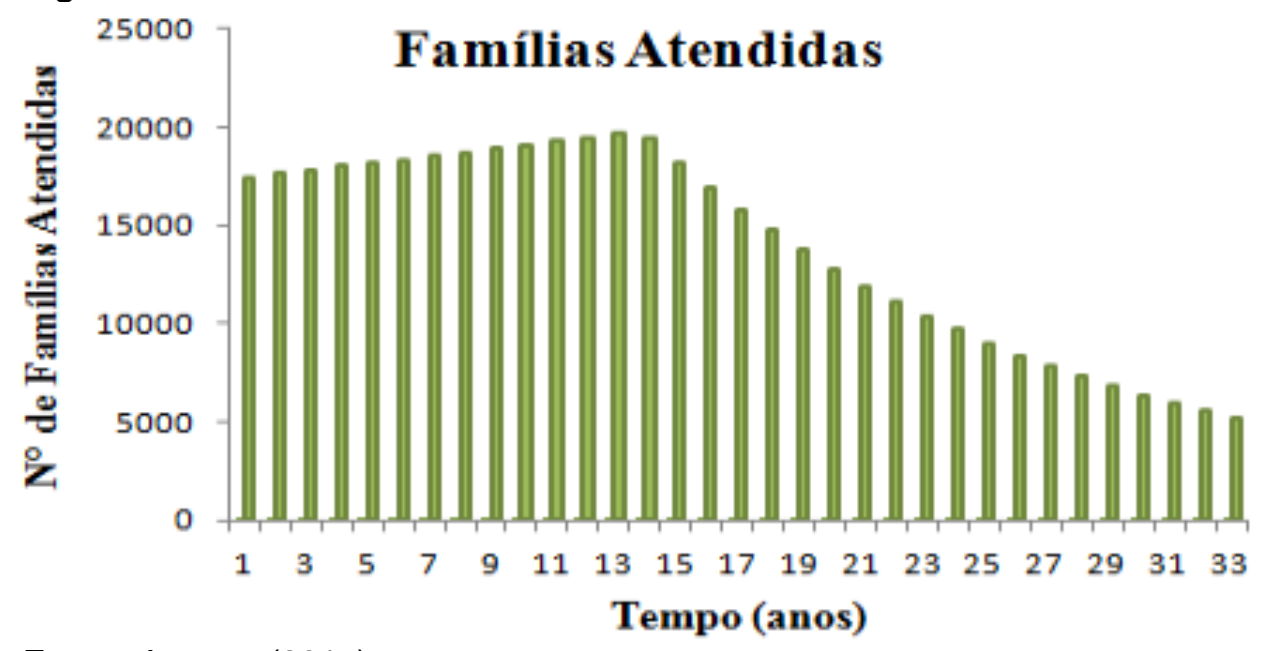

Fonte: Autores (2017)

Analisando a Figura 3, observa-se que, antes do encerramento de vida útil do aterro, o número de famílias atendidas vai crescendo, sendo que no $13^{\circ}$ ano calculado (ou seja, 20ำ ano de vida útil do aterro), quando ocorre o maior índice de geração de metano, a energia produzida pelo gás tem capacidade para atender 19.674 famílias, 
com uma capacidade máxima de energia a ser gerada de aproximadamente 38.000 MWh/ano.

Recentemente foi inaugurada uma usina de aproveitamento de biogás no aterro em estudo. Segundo a Asja Brasil (2017), empresa responsável pelo projeto e pela operação da usina, esta tem uma potência instalada de 5,7 MW, conta com uma capacidade de geração de $46.000 \mathrm{MWh} /$ ano de energia e atende 25.000 famílias anualmente.

Observando os valores obtidos no estudo e os valores reais do projeto original, é possível notar novamente uma coerência nos resultados encontrados. A pequena discrepância apresentada se deve ao fato de que os valores apresentados neste trabalho se referem a uma análise preliminar da possibilidade de utilização do biogás para geração de energia. Além disso, a utilização de modelos matemáticos exige informações que podem conter erros, principalmente por tratar-se de um modelo mais antigo e com poucas variáveis de identificação, possibilitando apenas uma aproximação aos possíveis resultados reais.

Vale ressaltar que, ao ocorrer o encerramento da vida útil do aterro, a quantidade de famílias a serem atendidas decresce. Isso acontece porque, como o aterro não se encontra mais em operação, não haverá mais depósito de RSU. Assim, a taxa de degradação da matéria orgânica presente reduz-se e, consequentemente, é gerada uma quantidade de $\mathrm{CH}_{4}$ menor a cada ano.

\subsection{Emissão de Gases de Efeito Estufa}

Os principais gases de efeito estufa (GEE) são o dióxido de carbono ( $\left.\mathrm{CO}_{2}\right)$, o metano $\left(\mathrm{CH}_{4}\right)$ e o óxido nitroso $\left(\mathrm{N}_{2} \mathrm{O}\right)$. As emissões de $\mathrm{CO}_{2}$ estão associadas ao uso de combustíveis fósseis e às mudanças de uso da terra, o $\mathrm{CH}_{4}$ provém de atividades agrícolas, da queima de combustíveis fósseis e de processos de decomposição anaeróbia, enquanto as emissões de $\mathrm{N}_{2} \mathrm{O}$ devem-se principalmente à agricultura (IPCC, 2007). O biogás advindo da decomposição de resíduos sólidos dos aterros sanitários é uma forma de minimizar o lançamento desses gases nocivos para o nosso planeta, pois, além de ser uma fonte alternativa de energia, evita que o gás metano nele contido seja emitido na atmosfera.

A Figura 4 evidencia a quantidade de $\mathrm{CH}_{4}$ que possivelmente será lançado di- 
retamente na atmosfera se não houver nenhum tipo de tratamento ou reaproveitamento. Como o metano tem potencial 25 vezes maior que o $\mathrm{CO}_{2}$ para aumento do efeito estufa, a queima do biogás equivalente que potencialmente seria impedido de alcançar a atmosfera da terra pode ser observado na Figura 5, que apresenta a quantidade de $\mathrm{CO}_{2 e q}$ emitido durante o período de vida útil do aterro.

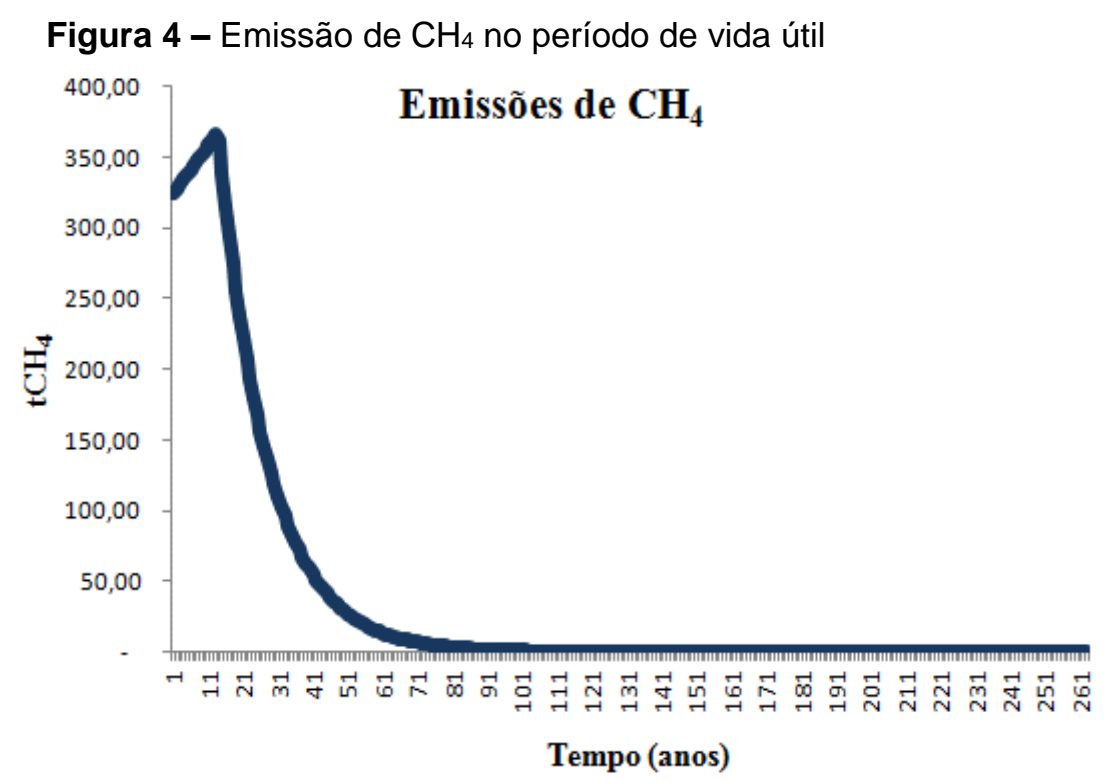

Fonte: Autores (2017)

Figura 5 - Emissão de $\mathrm{CO}_{2 e q}$ no período de vida útil

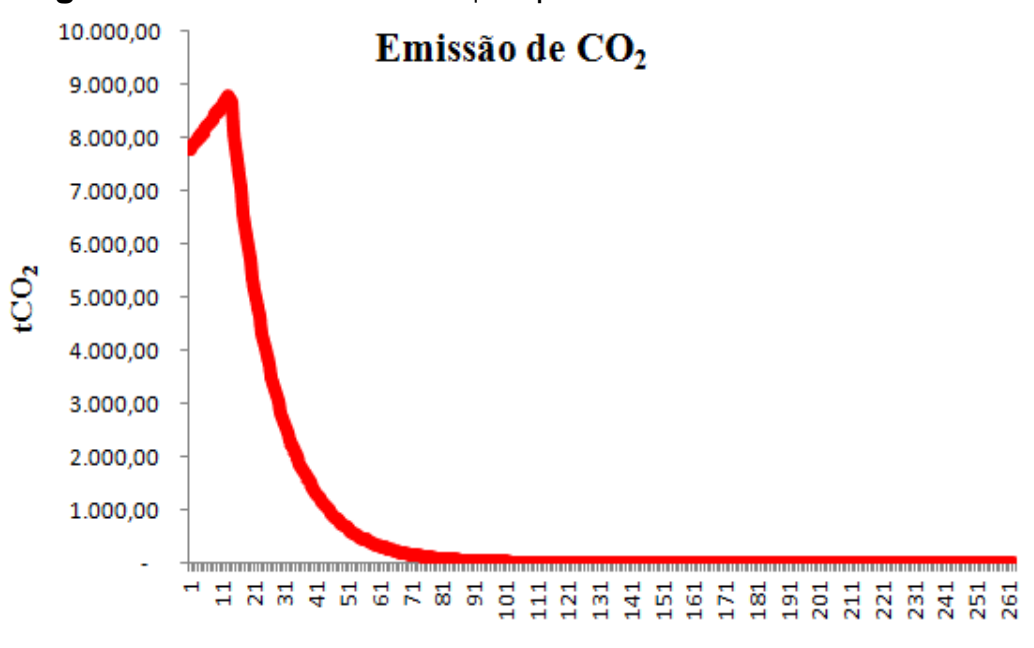

Fonte: Autores (2017)

Tempo (anos)

É possível observar que, no 13ํano de operação do aterro, tem-se o pico de emissões de metano e a emissão do equivalente em $\mathrm{CH}_{4}$. Caso não haja nenhum tratamento ou aproveitamento durante a vida do aterro em estudo, ou seja, todo o período desde o primeiro descarte de resíduo até a não ocorrência de geração de 
gases, e somando-se as emissões apresentadas na Figura 4, serão emitidas aproximadamente $9.838,44$ toneladas de $\mathrm{CH}_{4}$.

Comparando a Figura 4, que apresenta a emissão de $\mathrm{CH}_{4}$, e a Figura 5, com as emissões de $\mathrm{CO}_{2 e q}$, é possível observar que 1 tonelada de metano emitida é equivalente a 25 toneladas de dióxido de carbono (IPCC, 2007), sendo notório que a simples queima do gás metano no flare já seria um fator que minimizaria os efeitos danosos causados na atmosfera pelos GEE. Ainda mais benéfica é a utilização desses gases para geração de energia, pois resultaria na diversificação da matriz energética do Brasil e em vantagens econômicas e ambientais.

\section{CONCLUSÃO}

A diversificação da matriz energética brasileira por fontes renováveis tem sido um assunto bastante discutido nos últimos anos, devido ao aumento da demanda de energia elétrica e ao esgotamento dos combustíveis fósseis. Com isso, investir em fontes de energia como o biogás proveniente de aterros sanitários pode ser uma maneira favorável de tratar o problema, pois, além de trazer um benefício econômico, o gás metano produzido pela decomposição dos RSU é 25 vezes mais nocivo para a atmosfera do que o dióxido de carbono.

Neste trabalho identificou-se que o CTR Macaúbas em Sabará, MG, possui biogás para produção de energia elétrica, com uma potência máxima de energia a ser gerada no aterro de aproximadamente $38.000 \mathrm{MWh} /$ ano ocorrendo no $13^{\circ}$ ano, o que poderia abastecer mais de 19.000 famílias. No entanto, para verificar a viabilidade de instalação de uma usina de aproveitamento energético, recomendam-se estudos de viabilidade econômica e financeira.

Recomenda-se também que o aterro em estudo utilize equipamentos tipo flare, que são dispositivos utilizados na ignição e queima do biogás. De acordo com Barros (2013), o flare é considerado um componente de cada opção de recuperação de energia, visto que pode ser necessário durante as etapas de início do processo e manutenção dos sistemas, podendo também ser utilizado para queima de biogás excedente, evitando sua dispersão na atmosfera e minimizando o fenômeno de efeito estufa, caso ocorra necessidade de interromper o funcionamento da usina. 


\section{REFERÊNCIAS}

ABRELPE. Panorama do resíduos sólidos no Brasil 2015. 2015. Disponível em: <http://www.abrelpe.org.br/Panorama/panorama2015.pdf>. Acesso em 10 mai. 2017.

ASJA. Inauguração de uma nova planta de biogás 2017. Disponível em:

$<$ http://www.asja.energy/pt-br/noticias/asja-continua-crescer-no-brasil-inaugurada-novaplanta-de-biogas/>. Acesso em 06 nov. 2017.

BARROS, R. M. Tratado sobre resíduos sólidos: gestão, uso e sustentabilidade. Rio de Janeiro: Interciência; Minas Gerais: Acta, 2012.

BARROS, T. F. Geração de energia elétrica com biogás gerado em aterro sanitário. Porto Alegre, 2013. Disponível em:<https://www.lume.ufrgs.br/handle/10183/108427>. Acesso em 26 jul. 2018.

BRASIL. Ministério de Minas e energia. Secretária de Energia Elétrica. Boletim mensal de monitoramento do sistema elétrico brasileiro. Brasília, 2017. Disponível em:

<http://www.mme.gov.br/documents/10584/3308684/Boletim+de+Monitoramento+do+Sistema+El\%C3\%A9trico+-+Janeiro-2016. pdf/5977c97c-c5bf-433c-9c0a-b92cb32df517>.

Acesso em 27 out. 2017.

CASSAU FILHO, C.E.G. Potencial de geração de metano em aterros sanitários através dos modelos IPCC, USEPA e Scholl Canyon - Estudo de caso do Aterro Sanitário de Moskagen, Kamar, Suécia. Dissertação (Mestrado) - Universidade do Estado do Rio de Janeiro, Rio de Janeiro, 2012. Disponível em: < http://www.bdtd.uerj.br/tde_busca/arquivo.php?codArquivo=8169>. Acesso em 19 maio 2017.

CETESB - Companhia Ambiental do Estado de São Paulo. Biogás: geração e uso energético - versão 1.0/Cetesb. São Paulo, 2006. Disponível em: <http://www.cetesb.sp.gov.br/mudancasclimaticas/biogas/Softwares/16-Softwares\#>. Acesso em 28 ago. 2017.

CLIMATE DATA.ORG. Clima: Sabará. Disponível em:<https://pt.climate-data.org/location/24926/>. Acesso em: 19 maio 2017.

CRT MACAÚBAS S.A - Central de Tratamento De Resíduos Macaúbas S.A. Serviços. Disponível em: <www.ctrmacaubas.com.br/servicos/>. Acesso em 28 ago. 2017.

ELK, A.G.R.P.V. Mecanismos de desenvolvimento limpo aplicando a resíduos sólidos: Redução de emissões na disposição final. Rio de Janeiro, 2007. Disponível em:< http://www.mma.gov.br/estruturas/srhu_urbano/_publicacao/125_publicacao12032009023847>. Acesso em: 07 maio 2017.

EPA - United States Environmental Protection Agency. Landfill gas emissions model (LandGEM) - Version 3.02. 2005. Disponível em: < https://www3.epa.gov/ttncatc1/dir1/landgem-v302-guide.pdf>. Acesso em 28 ago. 2017.

EPE - Empresa de pesquisa Energética. Projeção da demanda de energia elétrica. Rio de Janeiro. Fevereiro, 2015. Disponível em: <http://www.epe.gov.br/>. Acesso em: 27 out. 2017. 
EPE - Empresa de pesquisa Energética. Resenha mensal do mercado de energia elétrica. Ano X, n. 113, Rio de Janeiro, 2017. Disponível em: <http://www.epe.gov.br/ResenhaMensal/Resenha\%20Mensal\%20do\%20Mercado\%20de\%20Energia\%20El\%C3\%A9trica\%20-\%20Janeiro\%202017.pdf>. Acesso em 27 out. 2017.

FELCA, A.T.A; GLÓRIA, R.F; BARROS, R.M; ALVES, A. P. Estimativa do potencial energético de um aterro sanitário por meio de duas metodologias. $8 \mathrm{fl}$. Poços de Caldas, 2015.

GIL, A. C. Como elaborar projetos de pesquisa. 4. ed. São Paulo: Atlas, 2008.

IPCC Fourth Assessment Report: Climate Change 2007 (AR4). Disponível em:<http://www.ipcc.ch/pdf/assessment-report/ar4/wg1/ar4-wg1-errata.pdf>. Acesso em 17 out. 2017.

MELLO, A.R; GRASSI, R. Avaliação do potencial de geração de energia elétrica a partir do biogás gerado no aterro sanitário do município de Francisco Beltrão - PR. $78 \mathrm{fl}$. Dissertação (Trabalho de Conclusão de Curso) - Universidade Tecnológica Federal do Paraná, Francisco Beltrão, 2014. Disponível em:< http://repositorio.roca.utfpr.edu.br/jspui/bitstream/1/2179/1/FB_COEAM_2013_2_04.pdf>. Acesso em 28 ago. 2017.

SABARÁ. Prefeitura Municipal. Secretaria Municipal de Educação e Cultura. Mapa da diversidade cultural de Sabará/MG. Sabará, 2017. Disponível em: < http://sabara.mg.gov.br/cultura/sobre-o-projeto/>. Acesso em 28 ago. 2017.

SAUER, I.L; VIEIRA, J. P; KIRCHNER, C. A.R. O Racionamento de energia elétrica decretado em 2001: Um estudo sobre as causas e as responsabilidades. $61 \mathrm{fls}$. Dissertação São Paulo, 2001. Disponível em:<http://www.iee.usp.br/sites/default/files/biblioteca/producao/2001/Monografias/ILDOEstudo\%20sobre\%200\%20Racionamento\%2015-12-2001.PDF>. Acesso em 15 mar. 2018.

VANZIN, E. Procedimento para análise da viabilidade econômica do uso do biogás de aterros sanitários para geração de energia elétrica: aplicação no aterro santa tecla. Dissertação (Pós-Graduação) - Faculdade de Engenharia e Arquitetura da Universidade de Passo Fundo. Passo Fundo, 2006. Disponível em: Acesso em: 24 nov. 2017.

WORLD BANK. Handbook for the preparation of landfill gas to energy projects in Latin America and the Caribbean. Conestoga-Rovers \& Associates, 2004. Disponível em: <http://documents.worldbank.org/curated/pt/954761468011430611/pdf/332640handbook.pdf>. Acesso em 28 ago. 2017. 